
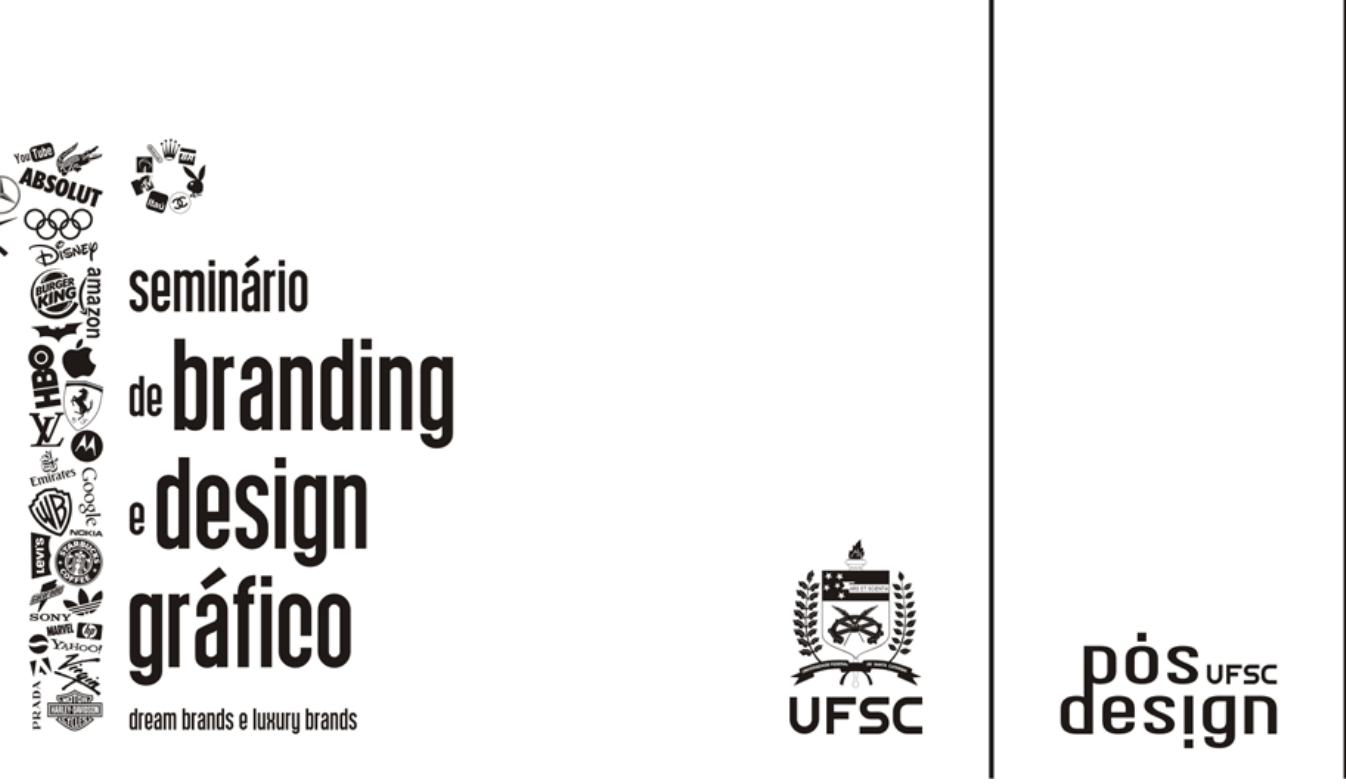

LOGO

\title{
A capacidade do branding na criação do conhecimento da marca
}

\author{
Branding's Capability on the Creation of the Brand's Knowledge \\ Silveira, Icleia; Doutoranda; Pontifícia Universidade Católica do Rio de Janeiro - PUC - Rio \\ c2iss@udesc.br
}

Silva, Giorgio Gilwan da; Especialista em Design Gráfico e Estratégia Corporativa; Universidade do Vale do Itajaí - UNIVALI

giorgiogilwan@gmail.com

\section{Resumo}

O presente artigo tem como objetivo abordar a identificação dos processos de criação do conhecimento usados na construção de uma marca forte, com a finalidade de complementar os modelos existentes. Foi desenvolvido através da metodologia qualitativa, por meio da análise da literatura. Neste sentido, aborda-se a teoria criada por Nonaka e Takeuchi (1997), sobre a criação do conhecimento. Os resultados comprovam que a construção de uma marca valiosa torna-se possível através da capacidade de branding, considerando os modos de conversão dos conhecimentos tácito e explícito, as habilidades de utilizar o patrimônio do conhecimento da marca, as experiências da marca e a criatividade para administrar os diferentes contextos, de atuação da marca.

Palavras-chave: marca, consumidor, identidade, conhecimento.

\begin{abstract}
This article aims to address the procedures identification for the creation of the knowledge used in building a strong brand, with the purpose of complementing existing models. It was developed through qualitative methodology, through the analysis of literature. Therefore, addresses to the theory created by Nonaka and Takeuchi (1997) on the creation of knowledge. The results show that the construction of a valuable brand becomes possible through the ability of branding, considering the ways of converting the explicit and tacit knowledge, the skills to use the assets of the brand's knowledge, the brand experience and creativity to manage the different contexts of the brand's action.
\end{abstract}

Keywords: brand, consumer, identity, knowledge 


\section{Introdução}

Esse artigo identifica como os processos de criação do conhecimento podem ser usados na construção das marcas valiosas. Para isso, aborda o modelo Aaker (1996) de identidade da marca e a teoria da criação do conhecimento através do processo criado por Nonaka e takeuchi (1997), em que o conhecimento é criado por meio da interação do conhecimento tácito e do conhecimento explícito. Busca-se neste âmbito, entender a capacidade do Branding, relacionado ao conhecimento das marcas nas corporações e o conhecimento da marca nos consumidores. A metodologia qualitativa foi construída, com base na análise crítica da literatura.

\section{A Identidade da Marca}

Neste trabalho adota-se o conceito de marca emocional de Gobé (2002, p.18), “[...] uma marca que se comunica com os consumidores no nível dos sentidos e das emoções, como uma marca ativa para as pessoas, forjando uma conexão profunda e duradoura".

Alguns autores como Gilmore, em Experience Economy, sugerem que a crescente importância do "valor experiencial" é a tendência mais significativa no ambiente mutante que envolve as marcas (GILMPORE,1999, apud Nonaka e Akutsu, 2008). O valor e a identidade das marcas focalizam o conhecimento codificado ou expresso através da linguagem (chamado de conhecimento explícito), porém o maior valor é o experiencial que é acumulado como conhecimento difícil de expressar através da linguagem (suposto conhecimento tácito).

Para construir o entendimento sobre os conhecimentos tácito e explícito, na criação da marca, trabalha-se com as teorias de Nonaka e Takeuchi (1997, p.61-82). Segundo estes autores, há dois tipos distintos de conhecimentos: o tácito e o explícito. O conhecimento tácito é pessoal, difícil de ser formulado e comunicado, inclui elementos cognitivos e técnicos. Os elementos cognitivos, modelos mentais, estabelecendo e manipulando analogias em suas mentes, e os elementos técnicos que incluem know-how concreto, técnicas e habilidades. O conhecimento explícito é adquirido principalmente pela educação formal e envolve o conhecimento dos fatos.

Alguns autores usam a noção de que o conhecimento da marca é definido com base no consumidor. Aeker (1998, p. 64), diz que "[...] é a capacidade que um comprador potencial tem de reconhecer ou de se recordar de uma marca como integrante de certa categoria de produtos." $\mathrm{O}$ que se defende nesse trabalho é a visão de Nonaka e Akutsu (2008, p.253), "[...] todo e qualquer conhecimento pode ser usado para criar o valor da marca", englobam todos os conhecimentos envolvidos na marca, inclusive os consumidores.

A teoria da criação do conhecimento organizacional, sobre a qual se baseia esse artigo, presume que o conhecimento humano seja criado e expandido através das interações sociais entre o conhecimento tácito e o conhecimento explícito. 


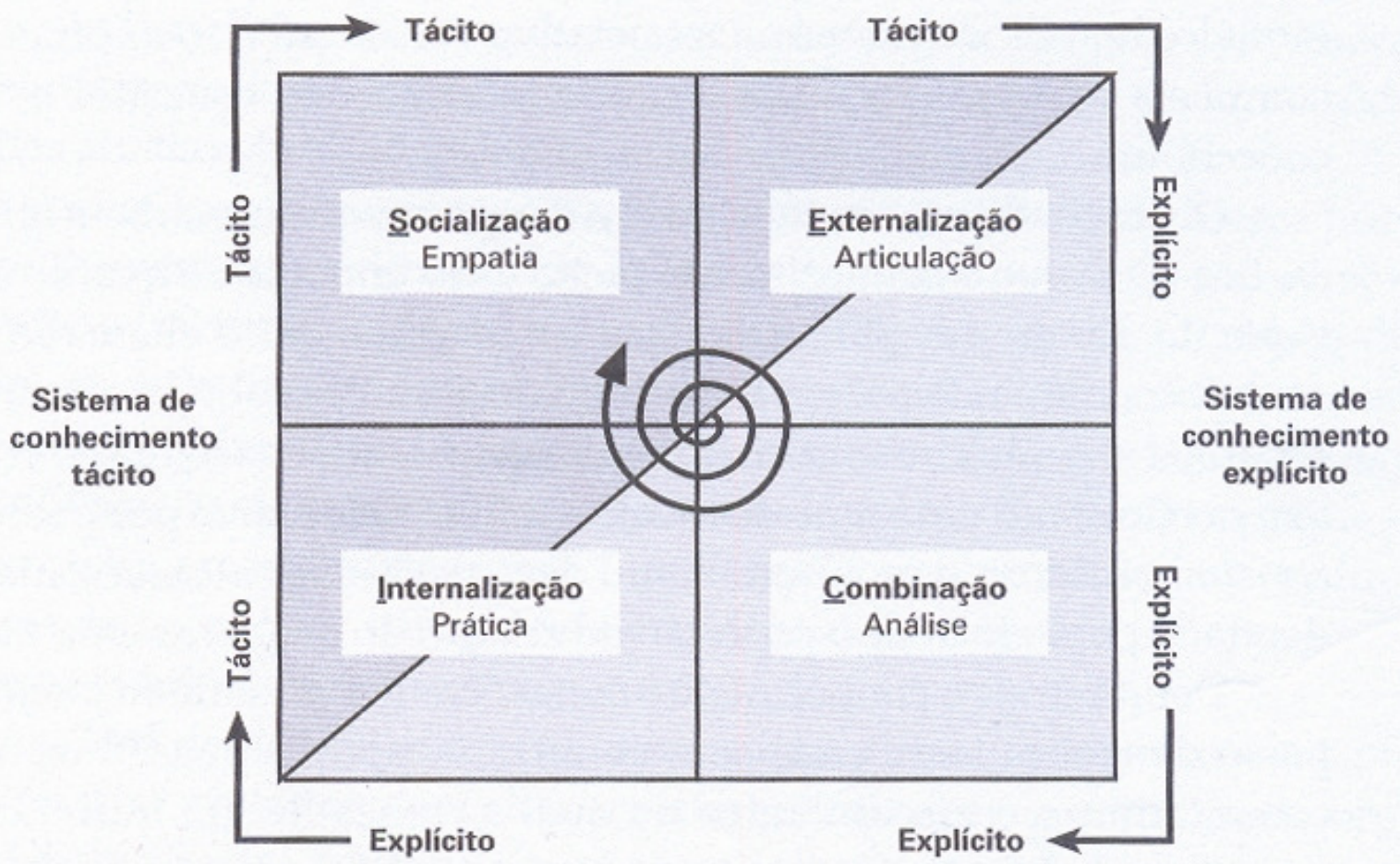

Figura 1: Modelo de Conversão do Conhecimento. Processo SECI.

Fonte: Adaptado de Nonaka e Takeuchi (1997, p. 69).

Conversão do conhecimento - Cada quadrante representa um dos quatro modos de conversão do conhecimento:

Socialização: processo de conversão do conhecimento tácito em conhecimento tácito. É um processo de compartilhamento de experiências e, a partir da criação do conhecimento tácito, como modelos mentais ou habilidades compartilhadas.

Externalização: processo de conversão do conhecimento tácito em conhecimento explícito. É o processo de criação do conhecimento, na medida em que o conhecimento tácito se torna explícito, expresso na forma de metáforas, analogias, conceitos, hipóteses e modelos.

Combinação: processo de conversão do conhecimento explícito em conhecimento explícito. É um processo de sistematização de conceitos em um sistema de conhecimento. Envolve a combinação de diferentes conjuntos de conhecimentos explícitos criando um novo conhecimento explícito.

Internalização: processo de incorporação do conhecimento explícito no conhecimento tácito. É o processo intimamente relacionado ao "aprender fazendo". Quando são internalizadas nas bases do conhecimento tácito dos indivíduos sob a forma de modelos mentais ou know-how técnico compartilhado.

\section{Processo de Criação do Conhecimento da Marca}

Nonaka e Akutsu (2008), usando a teoria do conhecimento organizacional e de uma noção ampliada do conhecimento da marca, redefinem o método de construção de marca como o processo de criação do conhecimento da marca focalizando somente as metodologias 
convencionais, introduzem um modelo complementar ao modelo da identidade da marca, usado por Aaker (1996). Figura 2.

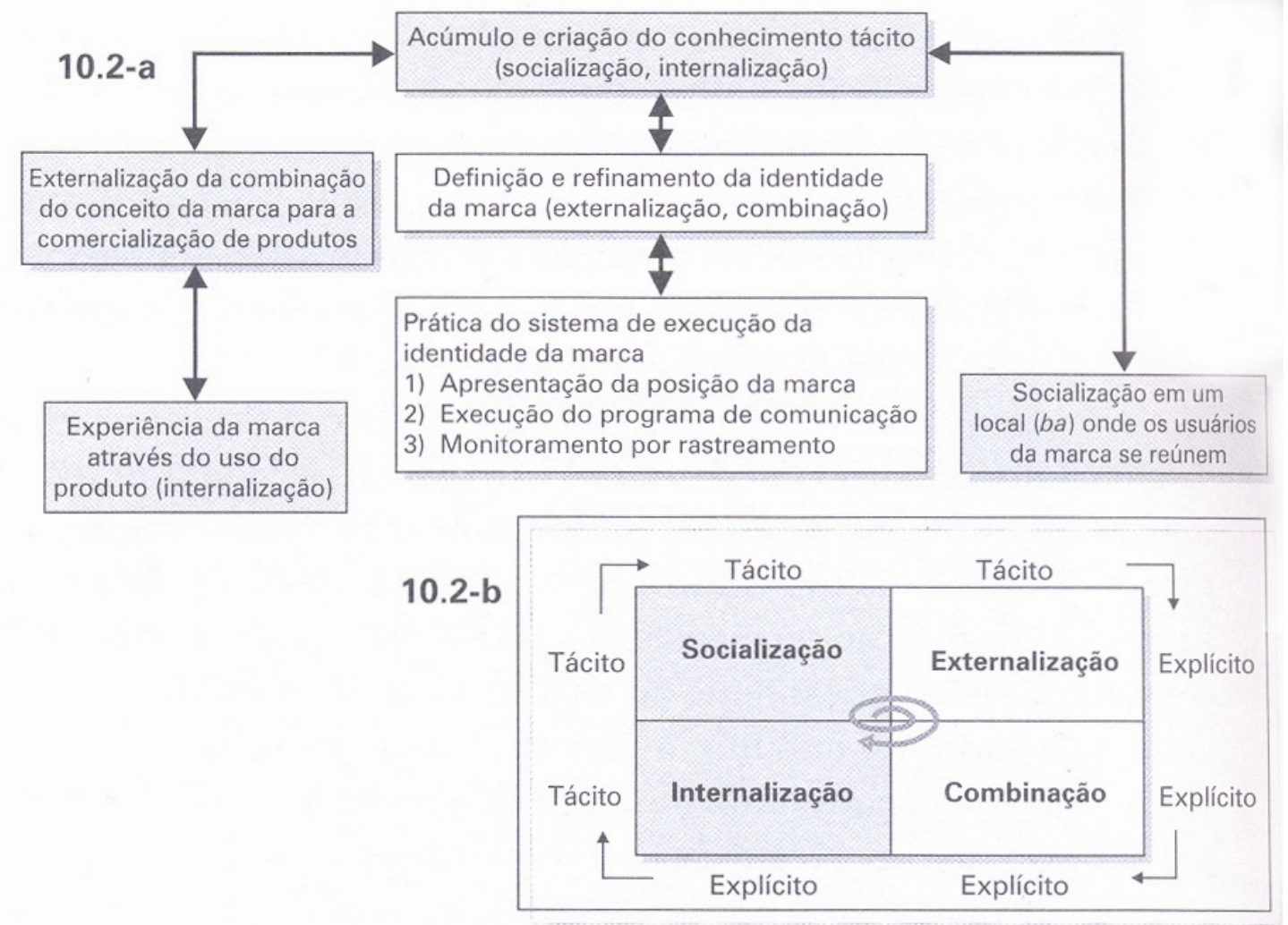

Figura 2: Modelo de Processo de Criação do Conhecimento da Marca

Fonte: Nonaka e Akutsu (2008, p. 258)

O processo de criação do conhecimento da marca - A discussão baseada no modelo de Aaker enfatiza o esclarecimento e a elaboração da identidade da marca, que correspondem aos processos de externalização e combinação do modelo de Nonaka e Akutsu (2008), pensando na marca não apenas como um produto, mas também como uma organização, pessoas e símbolos. Sendo assim, é possível acelerar a externalização (do tácito para o explícito) da identidade que foi expressa em palavras. A seguir, corre o processo de combinação (explícito e explícito).

A identidade que cria valor de marca é freqüentemente definida pela externalização (tácito para explícito), ou seja, do conhecimento obtido através da experiência direta, pela análise dos clientes, dos concorrentes e da própria empresa. O conhecimento tácito só é criado através do compartilhamento de experiências (socialização), do uso de produtos que incorporam o conhecimento explícito (internalização) e do emprego de manuais nos quais o know-how foi convertido em conhecimento explícito (internalização).

O modelo de Aaker (1996) apresenta três passos no "Sistema de Execução da Identidade da Marca": 1) Identidade da posição da marca, 2) implementação de um programa de comunicação, e 3) monitoramento do rastreamento contínuo.

$\mathrm{Na}$ visão de Nonaka e Akutsu, são métodos que se centralizam na comunicação de mensagens com ênfase na propaganda de massa, para comunicar sistematicamente ao cliente o 
conhecimento da marca que produz valor agregado. Nesse caso, o conhecimento tácito é externalizado em um conceito de marca e um produto é criado através do processo de combinação. Os consumidores internalizam, então, essas idéias, pensamentos e sentimentos incorporados através da experiência de uso.

$\mathrm{Na}$ figura 2, as seções sombreadas representam os processos que não são especificamente considerados nas discussões convencionais sobre identidade da marca (ver 2-a). Em termos do processo SECI, os processos de socialização e internalização, que criam o conhecimento tácito, estão faltando nos processos de conversão do conhecimento (ver 2-b). Com a construção de marca focalizada no conhecimento de marca, é muito importante proporcionar experiências de marca através do conhecimento tácito. As capacidades de Branding são capacidades organizacionais, baseadas no processo de conhecimento, que promovem efetivamente a seqüência completa de atividades para a construção da marca, como explicado no modelo acima.

\section{Capacidades de branding}

Nonaka e Akutsu (2008, p.253), apresentam cinco categorias da capacidade de Branding para construir marcas valiosas, focalizadas mais na capacidade de criar e compartilhar conhecimento tácito, internamente e com seus clientes. As capacidades do branding podem ser observadas na figura 3 e compreendidas na contextualização dos conceitos:

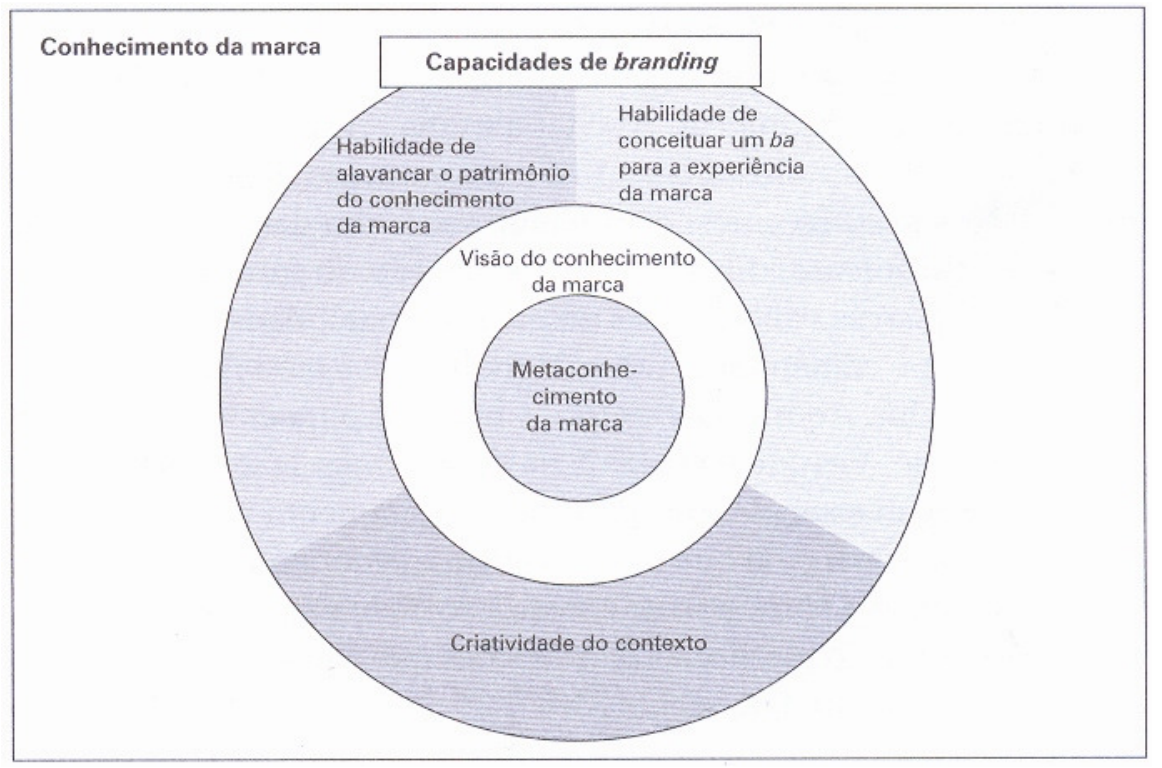

Figura 3: Capacidades de branding

Fonte: Nonaka e Akutsu (2008, p. 267)

Metaconhecimento da marca - O metaconhecimento da marca desempenha o papel de um modelo mental ou método de raciocínio, agindo como força impulsiva para as atividades que criam o conhecimento de marca valiosa. Como esse conhecimento origina novo conhecimento, os autores chamam de metaconhecimento para diferenciá-lo do conhecimento comum. É como uma metodologia que cria conhecimento sobre a marca para ser compartilhado em toda a organização. 
Visão do conhecimento da marca - Refere-se à direção que determina o tipo de conhecimento de marca que a organização deve criar para permanecer relevante, e ao que comanda a marca, inclusive suas promessas aos clientes. Proporciona uma identidade distinta à marca e possibilita um sistema de marca com efeitos sinérgicos. Como um "Contrato de Marca", não apenas o comando de como deve ser a marca existente, mas também sugeri os tipos de produtos que a organização deve desenvolver.

Habilidade de alavancar o patrimônio do conhecimento da marca - Trata-se do conhecimento da marca que uma organização conscientemente considera e administra, estrategicamente, com a finalidade de construir uma marca valiosa. Além de considerar como patrimônio o conhecimento dos clientes em relação a marca, considera também o metaconhecimento da marca, e a visão do conhecimento como patrimônio importante.

Habilidade de conceituar um ba Para a experiência da marca - Como um $b a$ ( local) para a experiência da marca, como uma força centrípeta. Se a própria marca funciona bem como um lugar para a experiência de marca, a criação do conhecimento de marca que envolve os clientes será promovida, e ele manterá sua energia e terá grande valor. O conhecimento da marca obtido pela experiência da marca é enriquecido tanto com os empregados como com os clientes, e com todos os envolvidos. O processo de internalização do uso do produto é a experiência de marca mais fundamental e poderosa.

Criatividade do contexto - A informação é interpretada pelos indivíduos e transformada em conhecimento de acordo com seus valores, mas depende também do que está sendo vinculado ao contexto em que está inserido. Por essa razão, o processo de criação do conhecimento da marca é considerado um processo de fazer contextos, no qual o próprio conhecimento de marca funciona. Se o processo de construção de marca for visto como um processo de criação dinâmica de contextos, a idéia de administrar os diferentes contextos é ativada.

Contextualizações finais - As discussões apresentadas sobre as capacidades de branding propõem um modelo para as práticas de construção de marca, que complementa a teoria da identidade da marca. Este modelo aplica a conversão do conhecimento, incluindo os consumidores e todas as pessoas envolvidas com a marca. Concentra-se no relacionamento entre o conhecimento da marca nas corporações e o conhecimento da marca nos consumidores. Entretanto, constatou-se que as capacidades de branding incluem fazer o máximo do conhecimento da marca com as partes, como os associados nos negócios, os acionistas, a comunidade local, os "intelectuais" e os "especialistas" na construção da marca. Utilizando a capacidade do branding, a construção de uma marca valiosa torna-se possível. Portanto, as corporações que desejam estabelecer marcas verdadeiramente valiosas devem assumir uma posição que permita que reconsiderem e redefinam suas filosofias administrativas, valorizando a criação do conhecimento

\section{Bibliografia}

AAKER, D. A. Criando e administrando marcas de sucesso. Tradução Bazán Tecnologia e Linguística. $2^{a}$ ed. São Paulo: Futura, 1996. 
AAKER, D. A. marcas - Brand Equity. Gerenciando o Valor da Marca.Tradução André Andrade. São Paulo: Negócios Editora, 1998.

GOBÉ, M. A Emoção das Marcas: conectando marcas às pessoas. Tradução de Fúlvio Lubisco. Rio de Janeiro: Campus, 2002.

NONAKA, Ikujiro; TAKEUCHI, Hirotaka; Criação de Conhecimento na Empresa. 13. ed. Rio de Janeiro: Elsevier, 1997.

NONAKA, Ikujiro; AKUTSU, Satoshi. Capacidades de Branding: Um olhar sobre a Capacidade da Sony na Criação do Conhecimento da Marca. In: IKUJIRO, Hirotaka e

NONAKA, Takeuchi. Gestão do Conhecimento; tradução Ana Thorell. Porto Alegre: Bookman, 2008. 